\title{
Risk Perception and Information Processing: The Development and Validation of a Questionnaire to Assess Self-Reported Information Processing
}

Citation for published version (APA):

Smerecnik, C. M. R., Mesters, I., Candel, M. J. J. M., de Vries, H., \& de Vries, N. K. (2012). Risk Perception and Information Processing: The Development and Validation of a Questionnaire to Assess Self-Reported Information Processing. Risk Analysis, 32(1), 54-66. https://doi.org/10.1111/j.15396924.2011.01651.x

Document status and date:

Published: 01/01/2012

DOI:

10.1111/j.1539-6924.2011.01651.x

Document Version:

Publisher's PDF, also known as Version of record

\section{Document license:}

Taverne

Please check the document version of this publication:

- A submitted manuscript is the version of the article upon submission and before peer-review. There can be important differences between the submitted version and the official published version of record.

People interested in the research are advised to contact the author for the final version of the publication, or visit the DOI to the publisher's website.

- The final author version and the galley proof are versions of the publication after peer review.

- The final published version features the final layout of the paper including the volume, issue and page numbers.

Link to publication

\footnotetext{
General rights rights.

- You may freely distribute the URL identifying the publication in the public portal. please follow below link for the End User Agreement:

www.umlib.nl/taverne-license

Take down policy

If you believe that this document breaches copyright please contact us at:

repository@maastrichtuniversity.nl

providing details and we will investigate your claim.
}

Copyright and moral rights for the publications made accessible in the public portal are retained by the authors and/or other copyright owners and it is a condition of accessing publications that users recognise and abide by the legal requirements associated with these

- Users may download and print one copy of any publication from the public portal for the purpose of private study or research.

- You may not further distribute the material or use it for any profit-making activity or commercial gain

If the publication is distributed under the terms of Article $25 \mathrm{fa}$ of the Dutch Copyright Act, indicated by the "Taverne" license above, 


\title{
Risk Perception and Information Processing: The Development and Validation of a Questionnaire to Assess Self-Reported Information Processing
}

\author{
Chris M. R. Smerecnik*, Ilse Mesters, Math J. J. M. Candel, Hein De Vries, and \\ Nanne K. De Vries
}

\begin{abstract}
The role of information processing in understanding people's responses to risk information has recently received substantial attention. One limitation of this research concerns the unavailability of a validated questionnaire of information processing. This article presents two studies in which we describe the development and validation of the Information-Processing Questionnaire to meet that need. Study 1 describes the development and initial validation of the questionnaire. Participants were randomized to either a systematic processing or a heuristic processing condition after which they completed a manipulation check and the initial 15item questionnaire and again two weeks later. The questionnaire was subjected to factor reliability and validity analyses on both measurement times for purposes of cross-validation of the results. A two-factor solution was observed representing a systematic processing and a heuristic processing subscale. The resulting scale showed good reliability and validity, with the systematic condition scoring significantly higher on the systematic subscale and the heuristic processing condition significantly higher on the heuristic subscale. Study 2 sought to further validate the questionnaire in a field study. Results of the second study corresponded with those of Study 1 and provided further evidence of the validity of the Information-Processing Questionnaire. The availability of this information-processing scale will be a valuable asset for future research and may provide researchers with new research opportunities.
\end{abstract}

KEY WORDS: Information processing; psychometric properties; reliability; risk perception; validity

\section{INTRODUCTION}

The role of information processing in understanding the effects of risk information on risk perception has recently received substantial attention. ${ }^{(1-5)}$ Current theorizing focuses on dual processes to explain how people respond to risks, examples of which concern affective versus cognitive processing (see, for instance, the risk-as-feeling

\footnotetext{
*Address correspondence to Chris Smerecnik, PO Box 616, 6200 MD, Maastricht, the Netherlands; tel: +31 43 3884278; fax: + 31 43 3671032; c.smerecnik@maastrichtuniversity.nl.
}

hypothesis $^{(6)}$ or the affect heuristic $\left.{ }^{(7)}\right)$ and experiential versus analytical systems. ${ }^{(8)}$ These dual-process accounts of risk perception all suggest, in one way or the other, that how a person processes information about a given risk will influence that person's risk perception.

Empirical support for this assumption has been provided by both observational ${ }^{(2,3)}$ and experimental studies. ${ }^{(5,9,10)}$ However, one limitation mentioned by several researchers concerns the unavailability of a validated scale to assess information processing. This article therefore describes two studies in which we developed such a scale, the Information-Processing 
Questionnaire (IPQ), and provide initial evidence concerning its reliability and validity.

\subsection{Dual Process Models and Risk Perception}

Contemporary cognitive psychological thought on information processing holds that individuals process information by using two qualitatively different pathways (but see Kruglanski and Thompson ${ }^{(11)}$ for a different view). This perspective is grounded in the social cognition literature and was developed to explain how people understand and derive meaning from the world around them. ${ }^{(12)} \mathrm{By}$ postulating a continuum of information processing anchored by systematic, analytic, or rational processing on one end and heuristic, experiential, or intuitive processing on the other, social psychologist have tried to elucidate this process. ${ }^{(12)}$ Such accounts of information processing have become known as dualprocess models and have since been applied to a large number of relevant outcomes such as stereotyping, ${ }^{(13,14)}$ attitudes, ${ }^{(15,16)}$ and, more recently, risk perception. ${ }^{(1-5,8,17)}$

One influential dual-process model, the Heuristic-Systematic Model (HSM), ${ }^{(15,18)}$ suggests that information can be processed systematically, heuristically, or by a combination of these two types of processing. Systematic processing is defined as "a comprehensive, analytic orientation in which perceivers access and scrutinize all informational input for its relevance and importance to their judgment task, and integrate all useful information in forming their judgments." (16,p.212) When processing information systematically, individuals thus make an effort to understand the information and how it relates to decision making (e.g., risk perception). In contrast, when processing information heuristically, individuals exert relatively little effort in processing the information. Instead, heuristic processing refers to focusing "on that subset of available information that enables them to use simple inferential rules, schemata, or cognitive heuristics to formulate their judgments or decisions."(16,p.213)

The HSM has recently been applied to risk perception research and has proven to be a valuable research paradigm to further our understanding of how people respond to various risks. For instance, Trumbo $^{(3)}$ assessed the value of the HSM to explain people's responses to information about cancer rates in their community. Differences in information processing as defined by the HSM accounted for a quarter to a third of variance in risk perception. Similar results have been obtained in other studies. ${ }^{(2,5)}$ Thus, the HSM has been shown to be a valuable tool for risk perception research.

\subsection{Measuring Information Processing}

Traditionally, information processing has been assessed by measuring responses to texts containing arguments of differing quality, ${ }^{(19)}$ people's overall cognitive responses to the text, ${ }^{(20)}$ or need for cognition (NFC). ${ }^{(21)}$ The former two measures are derivative by nature in the sense that type of information processing is derived from individuals' reaction to the information and usually require some manipulation of a text. The latter measure assesses a dispositional tendency or trait to "engage in and enjoy effortful cognitive endeavors"(21,p.306) and represents a personal characteristics that is assumed to be stable over time. Traits, however, may not fully account for an individual's information processing in a given setting due to contextual influences. Measures taking into account such contextual influences (i.e., state measures) will provide a better overview of that individual's information processing. (22) Although previous studies have made preliminary attempts to capture people's state processing styles more directly, ${ }^{(3,4,17)}$ no validated questionnaire to assess whether information has been processed systematically or heuristically has been developed to date-at least, to our knowledge. We therefore developed a questionnaire to assess people's state information processing as defined by the HSM.

The availability of a reliable and valid questionnaire to assess self-reported information processing may be a valuable asset to future research on information processing and risk communication and perception. The IPQ will advance research into risk perception in several ways and will provide new opportunities for theoretical and applied research. First of all, such a questionnaire will enable us to quickly gauge whether or not people have systematically processed any information we want them to consider. This is essential since systematic processing is an important precursor to informed consent, which ideally is the aim of risk communication. ${ }^{(23)}$ Second, from a theoretical perspective the ability to measure information processing directly could, for instance, be used to examine the relationship between heuristic and systematic processing and risk perception. From a practical perspective, being able to measure information processing would enable us to assess a risk communication's ability to motivate 
individuals to systematically process the information or to decrease the use of heuristics when processing the information within the material. In intervention studies it can be used to control for the effect of possible differences in processing styles between individual members of the experimental and control groups. A questionnaire to measure information processing on a self-report level may thus be expected to advance persuasion and communication research and provides researchers with new opportunities in risk perception research.

This article describes two studies, which resulted in the development and validation of the IPQ. The IPQ was devised to assess information processing as postulated by the HSM directly rather than indirectly or derivatively (i.e., as a state, rather than a trait). Study 1 describes the development and validation of the questionnaire, while Study 2 provides additional examination of the IPQ's properties and its relationship with risk perception.

\section{STUDY 1}

\subsection{Overview}

The goal of Study 1 was to create a reliable and valid questionnaire that was able to assess self-reported systematic and heuristic processing. Items were devised based on a literature search, semi-structured interviews, and pretesting, which resulted in an initial 15-item scale (for more details, see Section 2.2.4). This preliminary scale was then examined for reliability and validity.

\subsection{Method}

\subsubsection{Participants}

One hundred students (91 females; 9 males) of Maastricht University were invited to participate in this study. Students received $€ 7.50$ (approximately $\$ 10)$ for their participation in this study.

\subsubsection{Procedure and Design}

Upon arrival in the laboratory, participants were seated in front of a computer after which the procedure of the study was explained. Participants were told that they had to read a newspaper article about the link between salt intake and hypertension. The alleged purpose of the study was to examine the suitability of the article for different audiences. After giving written informed consent, participants answered questions concerning several socio-demographic characteristics. Participants were then randomly assigned to the systematic or the heuristic condition. Both groups were instructed to read a scenario on the relationship between salt intake and hypertension (see Section 2.2.3). Participants were instructed to carefully read and scrutinize the information as they would have to answer questions about how this information affected their daily life afterwards. For validation purposes we manipulated processing mode by (1) having participants in the heuristic-processing condition perform a secondary task while reading the target information, that is, they had to count the word "the" in the information and (2) by placing a constraint on the time they had available to process the information (i.e., 30 seconds; pilot testing showed that the scenario could be read once within this time constraint). These two instructions were expected to elicit heuristic processing as they would exclude the possibility to systematically process the information. ${ }^{(24)}$ After reading the scenario information, all participants were required to answer questions concerning comprehension of the information to check whether the processing manipulation was successful as well as the IPQ.

Participants were required to return two weeks later to enable us to establish the IPQ's test-retest reliability. The procedure of this follow-up was similar to the first measurement except that participants did not answer the questions concerning the sociodemographic characteristics. After completing the same questions as at the first session, participants were debriefed on screen. Before handing over the reward, participants were given the opportunity to ask any questions they might have.

\subsubsection{Materials}

The questionnaire and scenario were presented on screen using the Authorware 5.0 software package (Macromedia, Inc., 1987-1998). The scenario we used was based on a newspaper article that recently appeared in one of the larger daily newspapers in the Netherlands. It communicated information on the relationship between salt intake and hypertension, which has received renewed attention in the Dutch press after the Dutch Heart Foundation and the Dutch Center for Nutrition issued a report indicating that the Dutch general population consumes on average an excess of $4 \mathrm{~g}$ of salt each day. The newspaper article read as follows (translated from Dutch): "Researchers have announced that 
blood pressure responses to salt intake vary between people. Until recently, salt intake was assumed to elevate blood pressure and cause hypertension. Hypertension is an important risk factor for cardiovascular disease. In other words, if you are hypertensive, your risk of cardiovascular disease will increase. People over 50, women, and people of African descent are at increased risk of developing hypertension. Hypertension is also caused by lifestyle and genetic predisposition. The relationship between hypertension and salt intake is well-known. However, researchers have announced that this relationship does not apply to everyone. 'Not everyone is sensitive to salt in foods,' the project leader asserts. The research team advises people with a salt-sensitive blood pressure to restrict their salt intake in order to reduce their risk of cardiovascular disease."

\subsubsection{Development of the Information-Processing Questionnaire}

The IPQ was intended to measure people's information processing in terms of systematic and heuristic processing. During systematic processing people make an effort to understand the information and how it relates to existing knowledge and decision making, while during heuristic processing people focus on a subset of that information. ${ }^{(16,24)}$ Consequently, the questionnaire was developed to capture these distinguishing aspects of systematic and heuristic processing.

The IPQ was developed during several phases (see Table II for the final list of items). First, items assessing heuristic or systematic processing were adopted from previous research on the HSM and risk perception. ${ }^{(2-5,17)}$ These items were translated into Dutch using forward and backward translation. Second, we also conducted five semi-structured interviews with experts in either information processing or communication from the University. The interviews with the experts also yielded three additional items. The experts argued that among the heuristic items, we missed an item that assessed the use of information in decision making, an item that assessed the lack of elaboration, and one that assessed a prevalent heuristic in particular, namely, the "more is better" heuristic. We added these items to the IPQ. In total, we thus included seven items presumed to assess systematic processing and eight items presumed to assess heuristic processing in this study. All items were measured on a 7-point Likert scale (1 $=$ completely disagree $7=$ completely agree), such that higher scores on the systematic or heuristic items represent more systematic or heuristic processing, respectively.

The 15-item preliminary scale was then pretested among 25 students to ensure the questions were understandable. Using the plus-minus method combined with interview with five randomly selected students, this pretest revealed the need to rephrase several items due to differences in parlance and culture.

\subsubsection{Other Measures}

Sociodemographic characteristics. Participants were asked to report their age (in years), and their gen$\operatorname{der}(1=$ male, $2=$ female $)$. We also asked questions concerning participants' family history of hypertension and family history of salt sensitivity $(1=$ yes, 2 $=$ no, $3=$ don't know) as having a family history may be associated with higher levels of prior knowledge and thus facilitate comprehension of the scenario information.

Comprehension. Comprehension was measured to check whether the processing manipulation was successful. The measure of comprehension was based on the construction-integration model, ${ }^{(25)}$ which holds that information should become part of one's personal knowledge base. Based on this theory, two levels of comprehension can be distinguished: the text base and the situation model level. We used five open-ended questions to assess comprehension (see Table I; for a similar approach, see Smerecnik et al. $\left.{ }^{(26)}\right)$. The first question concerned participants' ability to reproduce the content of the information they had just read ("Describe in as much detail as possible the text you have just read."). The following four questions assessed the two levels of text comprehension: text base and situation model.(27) Answers to the two following text base questions were stated literally in the text (e.g., "According to the text, which factors cause hypertension?"). The answers to the two situation model questions require the participants to make inferences from the information in the text ${ }^{(28)}$ (e.g., "Miss Sulaweyo is a 60-year-old woman of African descent. Argue how your chances of developing hypertension differ from Miss Sulaweyo's."). To answer all these five questions correctly, participants had to report a total of 20 propositions (e.g., "I am less at risk than Miss Sulaweyo because I am a man and men are less at risk than women" is counted as one proposition). One point was awarded for each correctly judged 
Table I. Questions for the Text Base Level and Situation Model Level Comprehension Scale with Corresponding Scoring Scheme

\begin{tabular}{|c|c|c|c|}
\hline Question Type & Questions & Propositions Concerning & Scoring \\
\hline \multirow[t]{5}{*}{ General } & \multirow{5}{*}{$\begin{array}{l}\text { Describe in as much detail as possible the text you have just } \\
\text { read. }\end{array}$} & Hypertension/high blood pressure & 1 \\
\hline & & Salt intake & 1 \\
\hline & & $\begin{array}{l}\text { Link between salt intake and } \\
\text { hypertension is conditional }\end{array}$ & 1 \\
\hline & & Other risk factors & 1 \\
\hline & & Total & 4 \\
\hline \multirow[t]{10}{*}{ Text base level } & \multirow[t]{6}{*}{ According to the text, which factors cause hypertension? } & Genetic predisposition & 1 \\
\hline & & Age (50 years and over) & 1 \\
\hline & & Ethnicity & 1 \\
\hline & & Gender & 1 \\
\hline & & Diet & 1 \\
\hline & & Total & 5 \\
\hline & \multirow{4}{*}{$\begin{array}{l}\text { How does having a salt-sensitive blood pressure affect the } \\
\text { odds of developing hypertension? }\end{array}$} & Link salt and hypertension & 1 \\
\hline & & Difference gene present or not & 1 \\
\hline & & Explanation of this difference & 1 \\
\hline & & Total & 3 \\
\hline \multirow[t]{10}{*}{ Situation model level } & \multirow{6}{*}{$\begin{array}{l}\text { Miss Sulaweyo is a } 60 \text {-year-old woman of African descent. } \\
\text { Argue how your chances of developing hypertension differ } \\
\text { from Miss Sulaweyo's. }\end{array}$} & $\begin{array}{l}\text { Comparison based on: } \\
\text { Genetic predisposition }\end{array}$ & 1 \\
\hline & & Age & 1 \\
\hline & & Ethnicity & 1 \\
\hline & & Gender & 1 \\
\hline & & Diet & 1 \\
\hline & & Total & 5 \\
\hline & \multirow[t]{4}{*}{$\begin{array}{l}\text { Does the text recommend restriction of salt intake for } \\
\text { everyone? Explain your answer. }\end{array}$} & $\begin{array}{l}\text { Link genetic predisposition and } \\
\text { salt-sensitive blood pressure }\end{array}$ & 1 \\
\hline & & $\begin{array}{l}\text { Link salt-sensitive blood pressure and } \\
\text { hypertension }\end{array}$ & 1 \\
\hline & & Difference gene present or not & 1 \\
\hline & & Total & 3 \\
\hline
\end{tabular}

proposition resulting in 0-20 range for comprehension (see Table I for the complete scoring scheme). Answers to the comprehension questions were judged independently by two raters $(\mathrm{ICC}=0.75)$.

\subsubsection{Statistical Analyses}

Manipulation check. To check whether the processing manipulation was successful we performed an ANOVA with condition as the independent variable and the total comprehension score as the dependent variable.

Item suitability. Initial analyses were conducted to establish an item's usability. That is, we checked whether its scores were normally distributed and whether there were any floor or ceiling effects (defined as $15 \%$ or more of the participants having the lowest or highest possible score). Items with strongly skewed distribution or with floor or ceiling effects were removed from subsequent analyses. We then established an item's suitability for the scale. To this end, we first conducted a factor analysis to examine whether the total scale consisted of one or more factors. We used exploratory factor analyses using oblique rotation since this type of rotation allows for correlation between factors, although the degree of correlation that would be allowed among factors is rather small. ${ }^{(29)}$ The HSM posits that systematic and heuristic processing may co-occur in a given context $\mathrm{t}^{(16)}$ in either an additive manner (one type of processing complements the other ${ }^{(30)}$ ) or in a biasing manner (one type of processing biases the other type $\left.{ }^{(31)}\right)$. As a result scores on the systematic and heuristic subscales may correlate, which prompted us to use oblique rotation. A factor loading of 0.40 and over was deemed satisfactory for including an item in any of the identified subscales.

For each subscale we then established an item's suitability for the subscale by calculating the item's discrimination index, the item-total correlation, and the change in Cronbach's alpha after removing an item from the subscale. The discrimination index $d_{\mathrm{i}}$ is an index of the item's ability to discriminate between those having a high total score and those 
who have a low total score. ${ }^{(32)}$ Items with higher discrimination indices are better able to discriminate people with low versus higher scores on the subscale and are thus better suited for inclusion in the final version of the IPQ. The item-total correlation is an item's correlation with the total score of the subscale when that item is omitted and is thus a measure of how well an item fits the subscale. ${ }^{(32)}$ Higher item-total correlations indicate better fit with the other items within the subscale. Items with a relatively low discrimination index $(<0.30)$ or itemtotal correlation $(<0.30)$ were deleted from the scale. Subsequently, we deleted those items that upon deletion, substantially increased Cronbach's $\alpha(>0.10$ increase). The same procedure was followed for the data of the second measurement to ensure crossvalidation of the item suitability analyses.

Reproducibility. The resulting scale's reproducibility was assessed by examining the scale's agreement and reliability on two different occasions separated by a two-week interval. Agreement was determined using the intraclass correlation coefficient (ICC). Test-retest reliability was assessed using Pearson's correlation.

Construct validity. The scale's construct validity was examined by comparing the systematic and heuristic groups on the systematic-processing and heuristicprocessing subscales scores. We expected that participants in the systematic condition would score significantly higher on the systematic-processing subscale compared to those in the heuristic condition. In contrast, participants in the heuristic condition were expected to score higher on the heuristic-processing subscale compared to those in the systematic condition. To test these expectations, we performed ANOVAs with condition as the independent variable and systematic processing and heuristic processing as dependent variables. Cross-validation was established by conducting these analyses on the data of the first measurement and on the data of the second measurement.

\subsection{Results}

\subsubsection{Sample Characteristics}

Mean age of the research sample was 20.51 $(S D=2.29$; range: $18-31)$. The experimental groups did not differ in terms of age, gender, family history of hypertension, and family history of salt sensitivity ( $p$ s $>0.14)$.

\subsubsection{Manipulation Check}

Analysis of variance revealed a significant effect of condition on comprehension, $F(1,98)=75.13$, $p<0.001$. $^{1}$ Participants in the systematic condition had significantly higher comprehension scores $(M=$ $11.00, S D=2.88)$ than participants in the heuristic condition $(M=5.90, S D=3.00)$, suggesting a successful manipulation of processing style.

\subsubsection{Item Suitability}

Exploratory factor analysis with oblique rotation revealed two underlying factors (see Table II for factor loadings of the final scale). Factor 1 contained those items that assess whether individuals elaborately processed and thought about the information (i.e., systematic processing), while factor 2 contained items assessing whether individuals only focused on key points and did not think deeply about the information (i.e., heuristic processing). The systematicand heuristic-processing subscales seemed to be inversely correlated $(r=-0.51, p=0.001$ and $r=-$ $0.25, p=0.02$ on the first and second measurements, respectively), which may have been due to our processing manipulation. Two items did not reach the threshold for factor loadings on any of the two factors and were subsequently removed from the IPQ.

Table III presents an overview of the item characteristics. Based on the combination of the discrimination index and item-total correlation criteria, one item was removed from the questionnaire as this item scored uniformly low on both the discrimination index and the item-total correlation. ${ }^{2}$ Based on the criterion concerning Cronbach's $\alpha$, we observed that removal of two items resulted in higher Cronbach's $\alpha$. In addition, they had relatively low discrimination indices and, especially, item-total correlations compared to the other items in the systematic-processing subscale. Consequently, we decided to remove these two items from the IPQ.

\footnotetext{
${ }^{1}$ ANOVA's on the separate comprehension items also revealed significantly better performance among participants in the systematic condition than participants in the heuristic condition for all five items $(F \mathrm{~s}>11.44, p \mathrm{~s}<0.001)$.

${ }^{2}$ Although the discrimination index and item-total correlation of this item was significantly better on the second measurement, further analyses revealed a substantial increase in Cronbach's $\alpha$ after removal of this item (from to 0.57 to 0.68 ). This led us to remove this item from the IPQ.
} 
Table II. Factor Loadings of IPQ from Study 1 (Second Measurement Data Presented in Parentheses) and Study 2

\begin{tabular}{|c|c|c|c|c|}
\hline \multirow[b]{2}{*}{ Items } & \multicolumn{2}{|c|}{ Study 1} & \multicolumn{2}{|c|}{ Study 2} \\
\hline & $\begin{array}{l}\text { Systematic } \\
\text { Processing }\end{array}$ & $\begin{array}{l}\text { Heuristic } \\
\text { Processing }\end{array}$ & $\begin{array}{l}\text { Systematic } \\
\text { Processing }\end{array}$ & $\begin{array}{l}\text { Heuristic } \\
\text { Processing }\end{array}$ \\
\hline \multicolumn{5}{|l|}{ Systematic-processing items } \\
\hline $\begin{array}{l}\text { 1. I thought about what actions I myself might take based } \\
\text { on what I read }\end{array}$ & $0.81(0.82)$ & $-0.08(-0.11)$ & 0.76 & 0.18 \\
\hline $\begin{array}{l}\text { 2. I found myself making connections between the } \\
\text { information and what I've read or heard about elsewhere }\end{array}$ & $0.75(0.57)$ & $-0.39(-0.39)$ & 0.65 & 0.11 \\
\hline $\begin{array}{l}\text { 3. I thought about how the information related to other } \\
\text { things I know }\end{array}$ & $0.71(0.78)$ & $-0.09(-0.04)$ & 0.81 & -0.02 \\
\hline $\begin{array}{l}\text { 4. I tried to think about the importance of the information } \\
\text { for my daily life }\end{array}$ & $0.86(0.84)$ & $-0.11(-0.30)$ & 0.81 & -0.02 \\
\hline 5. I tried to relate the ideas in the information to my health & $0.82(0.82)$ & $-0.10(-0.31)$ & 0.64 & 0.18 \\
\hline \multicolumn{5}{|l|}{ Heuristic items } \\
\hline 6. I skimmed through the story & $0.12(-0.13)$ & $0.56(0.85)$ & 0.16 & 0.61 \\
\hline 7. I did not spend much time thinking about the information & $0.39(-0.20)$ & $0.74(0.83)$ & -0.02 & 0.83 \\
\hline $\begin{array}{l}\text { 8. The scenario did not contain useful information on which } \\
\text { I based my decision }\end{array}$ & $-0.06(0.15)$ & $0.67(0.37)$ & 0.10 & 0.84 \\
\hline $\begin{array}{l}\text { 9. While reading the information I did not think about the } \\
\text { arguments presented in the information }\end{array}$ & $0.15(-0.35)$ & $0.82(0.50)$ & 0.03 & 0.82 \\
\hline $\begin{array}{l}\text { 10. The information contained too many conflicting } \\
\text { viewpoints }\end{array}$ & $-0.36(-0.02)$ & $0.43(0.41)$ & 0.08 & 0.35 \\
\hline Eigenvalue & $4.79(3.52)$ & $1.31(1.70)$ & 2.90 & 2.48 \\
\hline$R^{2}$ (in percentage) & $47.94(35.22)$ & $13.12(16.96)$ & 28.97 & 24.84 \\
\hline
\end{tabular}

Note: Items in bold type exceed the threshold 0.40 value

Table III. Selecting Items for the IPQ in Study 1 (Second Measurement Data Presented in Parentheses) and Study 2

\begin{tabular}{|c|c|c|c|c|}
\hline \multirow[b]{2}{*}{ Items } & \multicolumn{2}{|c|}{ Study 1} & \multicolumn{2}{|c|}{ Study 2} \\
\hline & $\begin{array}{l}\text { Discrimination } \\
\text { Index }(\mathrm{d})\end{array}$ & $\begin{array}{l}\text { Item-Total } \\
\text { Correlation }\end{array}$ & $\begin{array}{l}\text { Discrimination } \\
\text { Index (d) }\end{array}$ & $\begin{array}{l}\text { Item-Total } \\
\text { Correlation }\end{array}$ \\
\hline \multicolumn{5}{|l|}{ Systematic Processing } \\
\hline \multicolumn{5}{|l|}{ While reading the information: } \\
\hline $\begin{array}{l}\text { 1. I thought about what actions I myself might take based } \\
\text { on what I read }\end{array}$ & $0.64(0.71)$ & $0.74(0.65)$ & 0.66 & 0.60 \\
\hline $\begin{array}{l}\text { 2. I found myself making connections between the } \\
\text { information and what I've read or heard about elsewhere }\end{array}$ & $0.40(0.27)$ & $0.67(0.66)$ & 0.55 & 0.41 \\
\hline $\begin{array}{l}\text { 3. I thought about how the information related to other } \\
\text { things I know }\end{array}$ & $0.60(0.62)$ & $0.61(0.57)$ & 0.64 & 0.67 \\
\hline $\begin{array}{l}\text { 4. I tried to think about the importance of the information } \\
\text { for my daily life }\end{array}$ & $0.68(0.73)$ & $0.79(0.77)$ & 0.58 & 0.66 \\
\hline 5. I tried to relate the ideas in the information to my health & $0.68(0.67)$ & $0.72(0.70)$ & 0.48 & 0.48 \\
\hline \multicolumn{5}{|l|}{ Heuristic Processing } \\
\hline 6. I skimmed through the story & $0.81(0.82)$ & $0.57(0.49)$ & 0.59 & 0.41 \\
\hline 7. I did not spend much time thinking about the information & $0.77(0.82)$ & $0.65(0.72)$ & 0.74 & 0.67 \\
\hline $\begin{array}{l}\text { 8. The scenario did not contain useful information on which } \\
\text { I based my decision }\end{array}$ & $0.45(0.35)$ & $0.67(0.78)$ & 0.60 & 0.63 \\
\hline $\begin{array}{l}\text { 9. While reading the information I did not think about the } \\
\text { arguments presented in the information }\end{array}$ & $0.45(0.52)$ & $0.62(0.40)$ & 0.53 & 0.62 \\
\hline $\begin{array}{l}\text { 10. The information contained too many conflicting } \\
\text { viewpoints }\end{array}$ & $0.40(0.19)$ & $0.58(0.45)$ & 0.20 & 0.22 \\
\hline
\end{tabular}


Based on the suitability analyses we thus selected five items for systematic processing (Cronbach's $\alpha=$ 0.71 and Cronbach's $\alpha=0.76$ for the first and second measurements, respectively ${ }^{3}$ ) and five items for heuristic processing (Cronbach's $\alpha=0.77$ and Cronbach's $\alpha=0.68$ for the first and second measurements, respectively). For each subscale, the five items were combined to form the corresponding factor (see Table II).

\subsubsection{Reproducibility}

The IPQ's reproducibility was examined by assessing the questionnaire's agreement and reliability. Agreement was assessed using the ICC. Analysis revealed an $\mathrm{ICC}_{\text {agreement }}$ of $0.79, p<0.001$ for a twoway random model with participants and moments of measurement as random factors for systematic processing; the ICC for heuristic processing was 0.76, $p<0.001$. Test-retest reliability was assessed by Pearson's correlation. Pearson's correlation for systematic processing was $r=0.78$; for heuristic processing, we observed a test-retest correlation of $r=0.75$.

\subsubsection{Validity}

For the first measurement data, analyses of variance revealed a significant effect of condition on systematic processing, $t(98)=5.98, p<0.001, \eta_{p}^{2}=$ 0.27 , and on heuristic processing, $t(98)=10.28, p<$ $0.001, \eta_{p}^{2}=0.52$. Participants in the systematic condition had higher scores on the systematic-processing subscale $(M=4.70, S D=1.01)$ than participants in the heuristic condition $(M=3.21, S D=1.45)$. In contrast, participants in the heuristic condition had higher scores on the heuristic-processing subscale $(M=4.34, S D=1.01)$ than participants in the systematic condition $(M=2.49, S D=0.77)$.

Analyses on the second measurement data confirmed these results, suggesting good cross-validity: ANOVA again revealed a significant effect of condition on systematic processing, $t(98)=3.67$, $p<0.001, \eta_{p}^{2}=0.22$, and on heuristic processing, $t(98)=4.07, p<0.001, \eta_{p}^{2}=0.15$. Similar to the first measurement data, participants in the system-

\footnotetext{
${ }^{3}$ Note that the Cronbach's $\alpha$ for factor 1 is calculated using scores from the systematic-processing group only and the Cronbach's $\alpha$ for factor 2 is calculated using scores from the heuristicprocessing group only. As such, the reported Cronbach's $\alpha$ s are thus an underestimation due to low variance of the true scores.
}

atic condition had higher scores on the systematicprocessing subscale $(M=4.60, S D=1.00)$ than participants in the heuristic condition $(M=3.41$, $S D=1.27)$; participants in the heuristic condition had higher scores on the heuristic-processing subscale $(M=4.31, S D=0.93)$ than participants in the systematic condition $(M=3.60, S D=0.81)$.

\subsection{Discussion}

The results of Study 1 suggest that the IPQ is a reliable and valid measure to assess self-reported information processing. Although slightly lower for the heuristic items than the systematic items, the resulting 10-item scale appeared to have adequate internal consistency, reproducibility, and validity.

With these results in mind, we conducted a second study to provide a more in-depth examination of the IPQ's properties. Essentially, Study 2 was conducted for three reasons. First, we examined the additional value of the IPQ over the NFC Scale. We deemed this especially important since the NFC Scale has been proven a valuable measurement tool in persuasion settings. NFC describes the dispositional tendency to engage in effortful processing (cf. systematic processing) and thus describes information processing as a trait, making it less responsive to the situational context. As our IPQ was posited to capture people's state information processing, the IPQ should be more strongly related to relevant outcomes measures (e.g., comprehension, risk perception) than the NFC. We thus examined whether the IPQ subscales were more strongly associated with comprehension than was the NFC Scale. If confirmed this would serve as evidence that the IPQ would have additional value over the NFC Scale. In addition, we expected NFC to be positively related to systematic processing but not to heuristic processing since the NFC Scale represents NFC as a unidimensional continuous scale.

Second, we sought to further validate the IPQ. As personal relevance has been argued to increase the odds of systematic processing, ${ }^{(16,24,33)}$ we examined whether participants for which the scenario information was personally relevant (i.e., participants with hypertension) would report higher systematic processing than participants for which the scenario information was not personally relevant.

Third, we aimed to assess the ecological validity of the IPQ by examining it in more real-life settings. To this end, we dropped the processing manipulations and tested the IPQ among a heterogeneous 
sample that was more characteristic of the general public than the sample used in Study 1.

In addition to these validation assessments of the validity of the IPQ, we were also interested in its relationship to risk perception. Previous research does not seem to provide a clear picture on how information processing affects risk perception. That is, while heuristic processing has often been linked to overreaction to risks, ${ }^{(34)}$ recent research has observed that systematic processing is related to higher risk perceptions while heuristic processing is related to lower risk perceptions. ${ }^{(2,3)}$ Based on the most recent research, we expected systematic processing to be positively related to risk perception while heuristic processing was hypothesized to be negatively related to risk perception.

\section{STUDY 2}

\subsection{Method}

\subsubsection{Participants}

Two hundred individuals were approached to participate in this study during the annual Spring Fair in Maastricht. Individuals were not rewarded for their participation in this study.

\subsubsection{Procedure}

Potential participants were approached at the annual Spring Fair in Maastricht and were asked to participate in this study. They were told the same cover story as participants in Study 1, namely, that they had to read a newspaper article about the link between salt intake and hypertension so we could examine the suitability of the article for different audiences. After giving verbal informed consent, participants were situated at a table and were asked to fill out the questionnaire, containing the same scenario and measures as Study 1 . The tables were situated in an open booth among the "health section" of the Spring Fair. Participants were tested individually with up to a maximum of five participants at any given timeslot. After having completed the questionnaire, participants returned it to the researcher. Participants were given the opportunity to ask any questions they might have concerning the survey or the topic under consideration (i.e., hypertension).

\subsubsection{Measures}

The questionnaire contained the same questions as the questionnaire in Study 1. That is, we assessed participants' comprehension of the scenario $(M=$ $8.71 ; S D=2.13)$, and the extent to which they engaged in systematic processing (Cronbach's $\alpha=0.80$; $M=3.70 ; S D=1.51$ ) and heuristic processing (Cronbach's $\alpha=0.74 ; M=4.33$; $S D=1.32$ ). In addition to these measures from Study 1, we added two measures in Study 2: the NFC scale and risk perception. To enable us to compare the systematic- and heuristic-processing subscales to the NFC Scale, we added the Dutch translation ${ }^{(35)}$ of the original NFC Scale. ${ }^{(21)}$ The 18 -item NFC Scale assesses individuals' preference for complex or simple problems and is thus related to how likely they are to process information systematically or heuristically. Example questions are "I would prefer complex to simple problems" and "I would prefer a task that is intellectual, difficult, and important to one that is somewhat important but does not require much thought." The items had good internal consistency (Cronbach's $\alpha=$ $0.78 ; M=3.52 ; S D=1.61$ ) and were therefore combined into the NFC factor.

To assess the relationship between the IPQ and risk perception, we assessed participants' risk perception with three questions on a 7-point Likert scale (e.g., "How much would you say you are at risk of developing hypertension?" $1=$ not at all at risk, $7=$ very much at risk). These three items showed adequate internal consistency and were thus combined to form the risk perception factor (Cronbach's $\alpha=$ $0.81 ; M=3.21 ; S D=1.89$ ).

\subsubsection{Statistical Analyses}

As in Study 1, we first performed analyses to examine an item's suitability for the corresponding subscales as revealed by confirmatory factor analyses with oblique rotation. To test whether the IPQ had any additional value over the NFC Scale, correlations were calculated to investigate the relationship between comprehension, systematic processing, heuristic processing, and NFC. We also assessed the correlations between the systematic- and heuristicprocessing scores, NFC, and risk perception to examine how the IPQ relates to risk perception.

\subsection{Results}

\subsubsection{Sample Characteristics}

In total, 161 individuals filled out and returned the questionnaire (response rate $=80.5 \%$ ). The sample consisted of 134 women and 27 men. Mean age of the research sample was $47.70(S D=16.51$; range: 
14-78). Twenty-three (13.1\%) participants reported being diagnosed with hypertension; 134 (76.6\%) reported not having hypertension; and the remaining $18(10.3 \%)$ participants reported to be unaware of whether or not they had hypertension.

\subsubsection{Selecting Items}

Confirmatory factor analysis with oblique rotation replicated the two initial factors identified in Study 1 (see Table II for factor loadings). Factor 1 contained those items that assess whether individuals elaborately processed and thought about the information (i.e., systematic processing), while factor 2 contained items assessing whether individuals only focused on key points and did not think deeply about the information (i.e., heuristic processing). The systematic- and heuristic-processing factors were not significantly correlated $(r=0.10, p=0.24)$. The same two items as in Study 1 did not reach the threshold for factor loadings on any of the two factors and were subsequently removed from the IPQ.

Table III presents an overview of the item characteristics. The suitability analyses showed that the items that were selected in Study 1 have good itemtotal correlations and discrimination indices; based on the criteria delineated in Study 1, the same items were selected for inclusion in the IPQ, confirming Study 1's item selection in a more ecologically valid sample and context. The systematic-processing subscale had good internal consistency (Cronbach's $\alpha=$ 0.80 ); as did the heuristic-processing subscale (Cronbach's $\alpha=0.74$ ).

\subsubsection{Validity}

Regarding construct validity, we predicted that participants for whom the scenario was personally relevant versus not personally relevant (i.e., operationalized as having hypertension and not having hypertension, respectively) would score higher on the systematic-processing scale. Analyses of variance revealed a significant effect of hypertension status on systematic processing $(F(2,154)=5.98, p<0.005)$, but not on the heuristic-processing scale, $F(2,151)=$ $1.73, p=18$. Participants with hypertension reported higher systematic-processing scores $(\mathrm{M}=5.06, S D$ $=1.35)$ than participants without hypertension $(\mathrm{M}=$ $4.47, S D=1.40$ ) or those who were unsure whether or not they had hypertension $(\mathrm{M}=3.36, S D=1.60)$, providing further evidence of the construct validity of the IPQ.
Concerning concurrent and discriminant validity, correlational analyses revealed a significant positive correlation for NFC with systematic processing $(r=0.50, p<0.001)$ but not with heuristic processing $(r=0.10, p>0.05)$. In addition, we observed a modest but significant correlation between systematic processing and comprehension $(r=0.19, p<$ $0.05)$, but not between NFC and comprehension $(r=$ $0.06, p>0.05$ ), or between heuristic processing and comprehension $(r=0.11, p>0.05)$.

\subsubsection{IPQ's Relation to Risk Perception}

Correlational analyses were conducted to examine the relationship between the IPQ, the NFC Scale, and risk perception. We restricted these analyses to participants who reported not knowing whether or not they had hypertension. We observed a significant positive correlation between systematic processing and risk perception $(r=0.35, p<0.001)$, and a smaller, but still significant, one between NFC and risk perception $(r=0.21, p<0.01)$. In addition, we observed a significant negative correlation between heuristic processing and risk perception $(r=-0.41, p$ $<0.001)$.

\subsection{Discussion}

The results observed in Study 1 were largely confirmed by the results of Study 2. Confirmatory factor analyses revealed the existence of two underlying factors: systematic processing and heuristic processing. Subsequent analyses suggest adequate discrimination indices and item-total correlations of the elected items as well as adequate internal consistency of the two subscales. Concerning our first goal (i.e., examining the additional value of the IPQ over the NFC Scale), the results generally support our expectations. As hypothesized, we observed significant correlations between comprehension and systematic processing, but not between comprehension and NFC. These results tentatively suggest that there is at least some merit in the self-report IPQ over the NFC Scale as a measure for information processing.

Concerning our second goal, we observed that participants for whom the scenario text was personally relevant (i.e., participants with hypertension) reported higher systematic processing than those for whom the scenario text was not personally relevant (i.e., participants who did not have or were unsure whether or not they had hypertension), providing further evidence of the validity of the IPQ. In 
addition, we replicated the results from Study 1 in a more realistic test situation indicating that the IPQ is ecologically valid as well.

Consistent with our expectations, the systematicprocessing subscale was positively related to risk perception while the heuristic-processing subscale was negatively related to risk perceptions. These results suggest that the IPQ has predictive value in terms of risk perception. However, as the data are crosssectional it may be too early to draw firm conclusions about the causality of the observed correlations. Nevertheless, Study 2 provides initial evidence that the IPQ is related to risk perceptions.

\section{GENERAL DISCUSSION}

This article described the development and validation of the IPQ, a self-report questionnaire to assess state information processing. Our analyses suggest that the questionnaire is reliable and valid. The scales were sensitive to our processing manipulation in Study 1 and to discriminating between people for whom the information was personally relevant (i.e., who had hypertension) and those for whom the information was not personally relevant (i.e., those without hypertension) in Study 2. Furthermore, the IPQ appears to have convergent and discriminant validity with the NFC Scale. As hypothesized, NFC was positively associated with systematic processing, but not with heuristic processing. Moreover, in our studies the IPQ seemed to outperform the NFC Scale in terms of its correlation with comprehension and risk perception scores. That is, while the systematicprocessing subscale was significantly related to comprehension of the scenario information, NFC was not. This may be explained by the fact that the IPQ is a self-report questionnaire that asks people to report how effortfully they have read the target information. As such, it may be able to take into consideration situation-specific factors that might influence information processing, something the NFC Scale is unable to do.

The results of the two studies presented in this article seem to suggest that the IPQ provides a reliable and valid tool for future research on information processing with new opportunities both for theoretical and applied research. The IPQ will enable us to quickly gauge whether or not people have systematically processed any information we want them to consider. This is essential since systematic processing is an important precursor to informed consent, which ideally is the aim of risk communication. ${ }^{(23)}$
From a theoretical perspective the IPQ could, for instance, be used to identify psychophysiological differences between heuristic and systematic processing or to examine the use of heuristics in systematic processing. From a practical perspective the IPQ can, for instance, be used to assess risk communications' ability to motivate individuals to systematically process the information or to decrease the use of heuristics when processing the information within the material. In intervention studies it can be used to control for the effect of possible differences in processing styles between the experimental and control groups.

There are several issues that need to be kept in mind when using the IPQ. First, the IPQ is a selfreport measure and as such represents people's subjective impression of their processing efforts. Following dual-process accounts of risk perception, ${ }^{(6-8)}$ researchers have recently focused on indirect or implicit measures of the heuristic, experiential, or affective processing of risk information. ${ }^{(36,37)}$ As a direct retrospective assessment the IPQ may be subject to the biases and limitations associated with such assessments. Indirect assessments, on the other hand, are presumed to be relatively resistant to such biases, but at the cost of being more time consuming and less easy to administer in the field. Both types of assessments have their advantages and disadvantages, but both are likely to explain unique variance of the target concept and thus both assessments have their merit based on the researcher's needs. The relationship between the direct and indirect measures and their relationship with risk perception needs to be examined in future research.

It is also important to note at this point that the IPQ was developed to capture state information processing and as such explicitly refers to the materials people were required to read. However, this may not be necessary or desirable in some contexts. In such cases, the wording of the IPQ may be slightly revised to meet the researcher's needs. For instance, instead of "While reading the information..." the researcher might use "When encountering information on the issue of...". Although this wording has not been validated as such and will not be able to capture people's state information processing, it may serve the purpose of estimating information processing in these contexts.

Aside from these conceptual issues, the studies presented in this article were subject to a number of limitations. The large majority of both samples were female and this may be problematic for generalization purposes. In similar vein, both studies focused 
on hypertension and generalization to other topics needs further investigation. However, a particular strength of the studies was that in Study 1 processing style was manipulated to develop and validate the IPQ and Study 2 assessed its ecological validity and its relationship with risk perception. This combination of experimental and observational research strengthens the trust we can have in the IPQ's reliability and validity.

A major limitation in current research on the role of information processing in risk perception is that there exists no validated questionnaire to assess how people process risk information. The IPQ meets that need and our results suggests it to be a reliable and valid scale to measure self-reported processing of (risk) information. Although the IPQ is ready to be utilized as a measure of information processing, future research should nonetheless examine the IPQ in more detail. Issues such as its relationship to indirect measures and standardization of the IPQ scores should receive extensive attention. These issues aside, the availability of this Information Processing Questionnaire will valuable asset for future research and may provide researchers with new research opportunities.

\section{ACKNOWLEDGMENTS}

This study was financially supported by Maastricht University and performed at the School for Public Health and Primary Care (Caphri). Caphri participates in the Netherlands School of Primary Care Research (CaRe), recognized by the Royal Dutch Academy of Science (KNAW) in 1995.

\section{REFERENCES}

1. Griffin RJ, Dunwoody S, Neuwirth K. Proposed model of the relationship of risk information seeking and processing to the development of preventive behaviors. Environmental Research, 1999; 80(2):230-245.

2. Trumbo $\mathrm{CW}$. Heuristic-systematic information processing and risk judgment. Risk Analysis, 1999; 19(5):391-400.

3. Trumbo CW. Information processing and risk perception: An adaptation of the heuristic-systematic model. Journal of Communication, 2002; 52(2):367-382.

4. Kahlor L, Dunwoody S, Griffin R, Neuwirth K, Giese J. Studying heuristic-systematic processing of risk communication. Risk Analysis, 2003; 23(2):355-368.

5. Kim J, Paek H-J. Information processing of genetically modified food messages under different motives: An adaptation of the multiple-motive heuristic-systematic model. Risk Analysis, 2009; 29(12):1793-1806.

6. Loewenstein GF, Weber EU, Hsee CK, Welch N. Risk as feelings. Psychological Bulletin, 2001; 127(2):267-286.

7. Finucane ML, Alhakami A, Slovic P, Johnson SM. The affect heuristic in judgments of risks and benefits. Journal of Behavioral Decision Making, 2000; 13(1):1-17.
8. Slovic P, Finucane ML, Peters E, MacGregor DG. Risk as analysis and risk as feelings: Some thoughts about affect, reason, risk, and rationality. Risk Analysis, 2004; 24(2):311322.

9. Denes-Raj V, Epstein S. Conflict between intuitive and rational processing: When people behave against their better judgment. Journal of Personality and Social Psychology, 1994; 66(5):819-829.

10. van Gelder J-L, de Vries RE, van der Pligt J. Evaluating a dual-process model of risk: Affect and cognition as determinants of risky choice. Journal of Behavioral Decision Making, 2009; 22(1):45-61.

11. Kruglanski AW, Thompson EP. Persuasion by a single route: A view from the unimodel. Psychological Inquiry, 1999; 10(2):83-109.

12. Moskowitz GB, Skurnik I, Galinsky AD. The history of dual-process notions, and the future of preconscious control. In Chaiken S, Trope Y (eds). Dual-Process Theories in Social Psychology. New York: Guilford Press, 1999.

13. Fiske ST, Lin M, Neuberg SL. The continuum model. Ten years later. In Chaiken S, Trope Y (eds). Dual Process Theories in Social Psychology. New York: Guilford Press, 1999.

14. Brewer MB, Feinstein ASH. Dual processes in the cognitive representation of persons and social categories. In Chaiken S, Trope Y (eds). Dual Process Theories in Social Psychology. New York: Guilford Press, 1999.

15. Chaiken S. Heuristic versus systematic information processing and the use of source versus message cues in persuasion. Journal of Personality and Social Psychology, 1980; 39(5):752-766.

16. Chaiken S, Liberman A, Eagly A. Heuristic and systematic information processing within and beyond the persuasion context. In Uleman JS, Bargh JA (eds). Unintended Thought. New York: Guilford Press, 1989.

17. Griffin RJ, Neuwirth K, Giese J, Dunwoody S. Linking the Heuristic-Systematic Model to depth of processing. Communication Research, 2002; 29(6):705-732.

18. Chaiken S. The heuristic model of persuasion. In Zanna MP, Olson JM, Herman CP (eds). Social Influence: The Ontario Symposium. Hillsdale, NJ: Erlbaum, 1987.

19. Cacioppo JT, Petty RE, Morris KJ. Effects of need for cognition on message evaluation, recall, and persuasion. Journal of Personality and Social Psychology, 1983; 45(4):805818.

20. Maheswaran D, Meyers-Levy J. The influence of message framing and issue involvement. Journal of Marketing Research, 1990; 27:361-367.

21. Cacioppo JT, Petty RE, Kao CF. The efficient assessment of need for cognition. Journal of Personality Assessment 1984; 48(3):306-307.

22. Steyer R, Schmitt M, Eid M. Latent state-trait theory and research in personality and individual differences. European Journal of Personality, 1999; 13(5):389-408.

23. National Research Council. Improving Risk Communication. Washington, DC: National Academy Press, 1989.

24. Chen S, Chaiken S. The Heuristic-Systematic Model in its broader context. In Chaiken S, Trope Y (eds). Dual-Process Theories in Social Psychology. New York: Guilford Press, 1999.

25. Kintsch W. The role of knowledge in discourse comprehension: A construction-integration model. Psychological Review, 1988; 95(2):163-182.

26. Smerecnik CMR, Mesters I, Kessels LTE, Ruiter RAC, de Vries NK, de Vries H. Understanding the positive effects of graphical risk information on comprehension: Measuring attention directed to written, tabular, and graphical risk information. Risk Analysis, 2010; 30(9):13871398. 
27. Hofman R, Van Oostendorp H. Cognitive effects of a structural overviewing of a hypertext. British Journal of Educational Technology, 1999; 30(2):129-140.

28. Kools M, Van de Wiel MWJ, Ruiter RAC, Crüts A, Kok G. The effect of graphic organizers on subjective and objective comprehension of a health education text. Health Education and Behavior, 2006; 33(6):760-772.

29. Basilevsky A. Statistical Factor Analysis and Related Methods: Theory and Applications. New York: John Wiley \& Sons, Inc., 1994.

30. Maheswaran D, Chaiken S. Promoting systematic processing in low-motivation settings: Effects of incongruent information on processing and judgment. Journal of Personality and Social Psychology, 1991; 61(1):13-25.

31. Chaiken S, Maheswaran D. Heuristic processing can bias systematic processing: Effects of source credibility, argument ambiguity, and task importance on attitude judgment. Journal of Personality and Social Psychology, 1994; 66(3):460-473.

32. Streiner DL, Norman GR. Health Measurement Scales. A
Practical Guide to Their Development and Use. 2nd ed. Oxford: Oxford University Press, 2003.

33. Petty RE, Cacioppo JT. Communication and Persuasion: Central and Peripheral Routes to Attitude Change. New York: Springer-Verlag, 1986.

34. Lopes LL. The rhetoric of irrationality. Theory and Psychology, 1991; 1(1):65-82.

35. Pieters RG, Verplanken B, Modde JM. "Neiging tot nadenken": Samenhang met beredeneerd gedrag. [Leaning toward reflection: The connection with reasoned behavior.] Nederlands Tijdschrift voor de Psychologie en haar Grensgebieden, 1987; 42(2):62-70.

36. Dohle S, Keller C, Siegrist M. Examining the relationship between affect and implicit associations: Implications for risk perception. Risk Analysis, 2010; 30(7):1116-1128.

37. Visschers VHM, Meertens RM, Passchier WF, de Vries NK. Audiovisual risk communication unraveled: Effects on gut feelings and cognitive processes. Journal of Risk Research, 2008; 11(1):207-221. 